\title{
Oleate epoxidation in a confined matrix of hydrotalcite
}

Daniel Cosano, Dolores Esquivel, Francisco J. Romero-Salguero, César JiménezSanchidrián, José Rafael Ruiz*

Departamento de Química Orgánica, Instituto Universitario de Investigación en Química Fina y Nanoquímica IUIQFN, Facultad de Ciencias, Universidad de Córdoba, Campus de Rabanales, Edificio Marie Curie, E-14071 Córdoba, Spain

\footnotetext{
* Corresponding author. E-mail address: qo1ruarj@uco.es. Phone no.: 34957 218638. Fax no.: 34 957212066
} 
Figure S1. XRD patterns for the epoxidized hydrotalcites: (a) HT-OLE-EXC-EPO and (b) HT-OLE-MW-2-EPO.

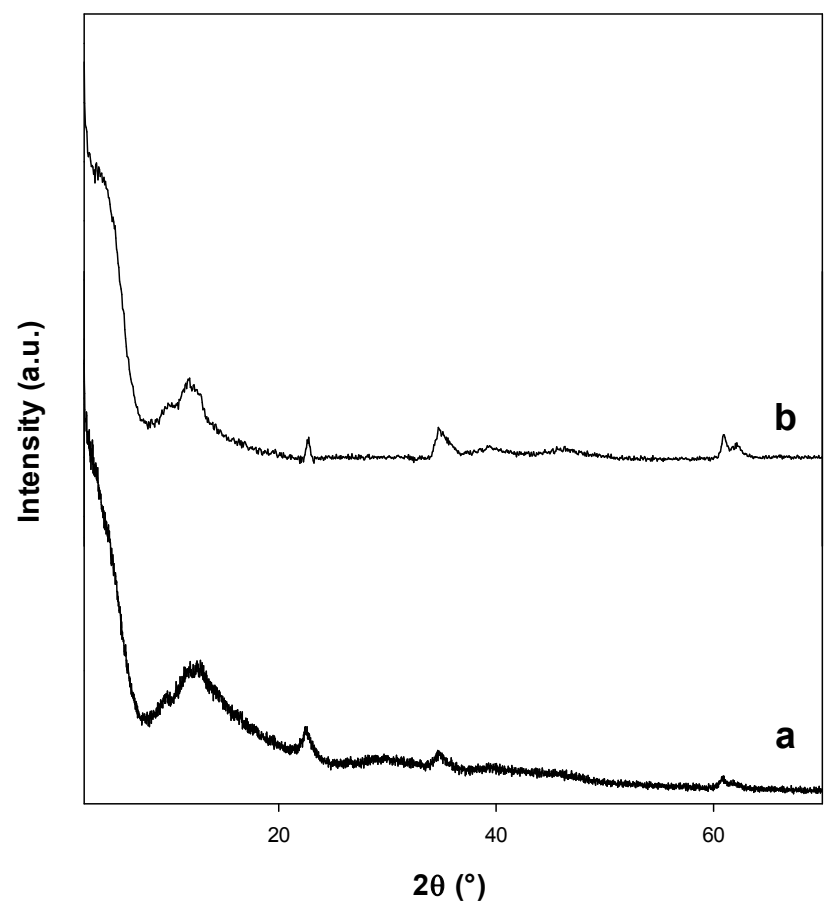


Figure S2. Raman spectra in the $150-4000 \mathrm{~cm}^{-1}$ region for $m$ CPBA (a), HT-OLE-EXCEPO (b) and HT-OLE-MW-2-EPO (c).

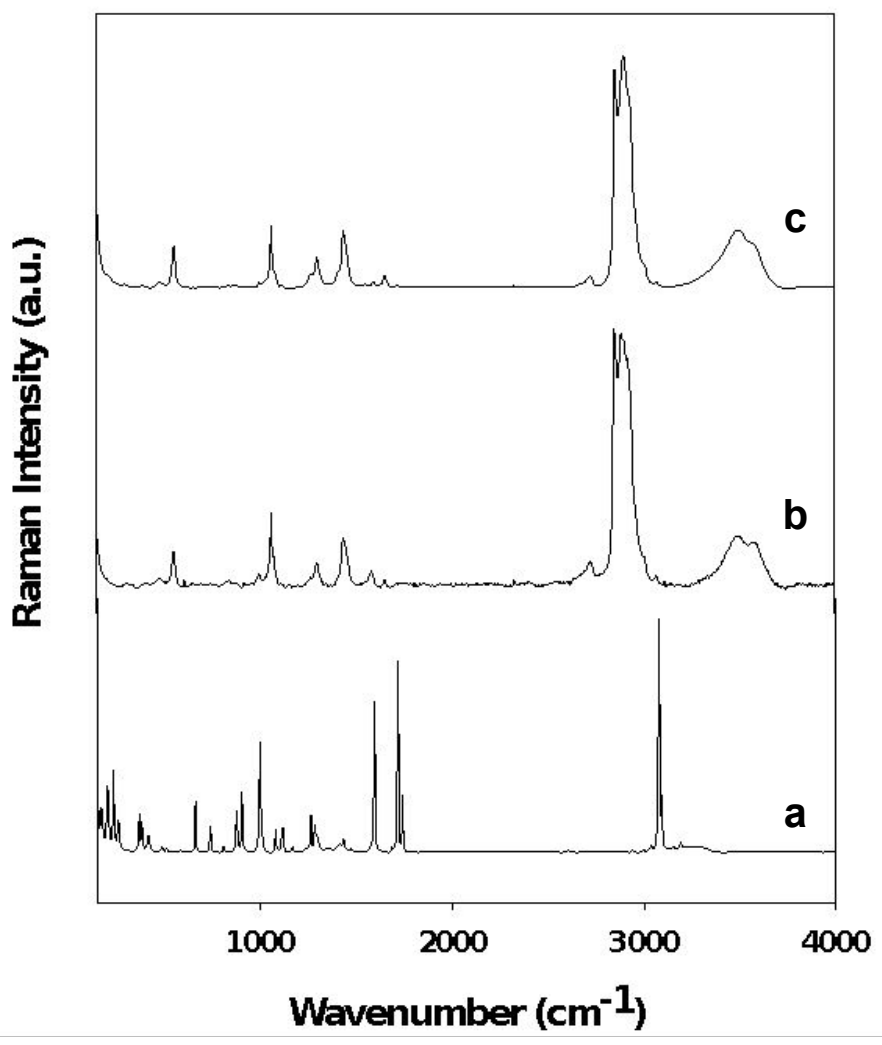

